\title{
Supine Hypotension Syndrome pada Kehamilan
}

\author{
Dewi Yulianti Bisri, ${ }^{1,2}$ Ike Sri Redjeki, ${ }^{1,2}$ Tatang Bisri ${ }^{1,2}$ \\ ${ }^{1}$ Departemen Anestesiologi dan Terapi Intensif Fakultas Kedokteran Universitas Padjadjaran/Rumah Sakit Dr. \\ Hasan Sadikin Bandung, ${ }^{2}$ Melinda Women Hospital Bandung
}

\begin{abstract}
Abstrak
Supine hypotension syndrome (SHS) dapat terjadi mulai kehamilan trimester 2 dan didefinisikan sebagai penurunan tekanan sistol $\geq 30 \%$ pada posisi supine dibanding dengan lateral. Tujuan penelitian mengetahui insidensi SHS pada wanita hamil aterm di Indonesia. Penelitian observasional pada 200 wanita hamil aterm, kehamilan pertama dan kedua, usia 18-40 tahun, tidak memiliki penyakit sertaan, dan akan dilakukan seksio sesarea elektif di Rumah Sakit Ibu dan Anak Melinda dalam periode Maret-Juli 2012. Pasien diberikan 500 cc cairan kristaloid Ringer laktat sebagai pengganti puasa, kemudian dilakukan pemeriksaan tekanan sistol, diastol, rata-rata, laju nadi, dan saturasi oksigen selama 5 menit dengan jarak 1 menit pada posisi supine dan miring kiri $45^{\circ}$. Hasil pengukuran tekanan sistol supine $113,49(13,20) \mathrm{mmHg}$, miring $105,20(12,08) \mathrm{mmHg}$ dengan nilai $\mathrm{p}=0$,93. Tekanan diastol supine 69,05 $(7,31) \mathrm{mmHg}$ dan miring 58,58 $(7,73) \mathrm{mmHg}(\mathrm{p}=0,51)$. Tekanan darah ratarata supine $84,59(8,38) \mathrm{mmHg}$ dan miring $75,87(8,82) \mathrm{mmHg}(\mathrm{p}=0,62)$. Laju nadi supine $88,95(12,19) \times / \mathrm{menit}$, dan miring 86,26 (11,47)x/menit, $(\mathrm{p}=0,86)$. $\mathrm{SpO}_{2}$ supine 99,95 $(1,11) \%$ dan miring 99,64 $(0,67) \%(\mathrm{p}=0,07)$. Simpulan, tidak ada perbedaan tekanan sistol, diastol, rata-rata, laju nadi, dan $\mathrm{SpO}_{2}$ wanita hamil aterm pada posisi berbaring dengan posisi miring kiri 45². [MKB. 2015;47(2):109-14]
\end{abstract}

Kata kunci: Posisi supine, posisi miring kekiri, supine hypotension syndrome, wanita hamil aterm

\section{Supine Hypotension Syndrome in Pregnancies}

\begin{abstract}
Supine hypotension syndrome (SHS) can occur starting from the second trimester of pregnancy and is defined as a reduction of systolic blood pressure of $\geq 30 \%$ in the supine position compared to lateral position. The purpose of this study was to determine the incidence of SHS in full term pregnant women in Indonesia. An observational study on 200 full term pregnant women, first and second pregnancy, aged 18-40 years, no coexisting diseases, and was going to have an elective cesarean section in Melinda Woman and Child Hospital in the period of MarchJuly 2012. Patients were given 500 cc of Ringer's lactate crystalloid fluid instead of fasting. Systolic and diastolic blood pressure, mean blood pressure, pulse rate, and oxygen saturation for 5 minutes were then examined every minute. The examination was conducted in the supine and left lateral position of $45^{\circ}$. The results show a systolic blood pressure in supine position of 113.49 (13.20) $\mathrm{mmHg}$ and in lateral position of $105.20(12.08) \mathrm{mmHg}$ $(\mathrm{p}=0.93)$. Meanwhile, the supine diastolic blood pressure was 69.05 (7.31) $\mathrm{mmHg}$ and lateral position was 58.58 (7.73) $\mathrm{mmHg}(\mathrm{p}=0.51)$. The mean blood pressure in supine position was 84.59 (8.38) $\mathrm{mmHg}$ and 75.87 (8.82) $\mathrm{mmHg}(\mathrm{p}=0.62)$ in lateral position. The pulse rates for supine and lateral position were $88.95(12.19) \mathrm{x} / \mathrm{min}$ and 86.26 (11.47) x/min (p=0.86), respectively. Supine $\mathrm{SpO}_{2}$ was 99.95 (1.11)\% and lateral $\mathrm{SpO}$ was $99.64(0.67) \%$ $(\mathrm{p}=0.07)$. In conclusion, there is no differences in systolic, diastolic, mean blood pressure, pulse rate and $\mathrm{SpO}_{2}$ of full term pregnant women in supine or left lateral position of 45 . [MKB. 2015;47(2):109-14]
\end{abstract}

Key words: Full term pregnant women, left lateral decubitus, supine hypotension syndrome, supine

Korespondensi: Dewi Yulianti Bisri, dr., Sp.An-KNA, KAO, M.Kes Departemen Anestesiologi dan Terapi Intensif Fakultas Kedokteran Universitas Padjadjaran/Rumah Sakit Dr. Hasan Sadikin Bandung, Jalan Pasteur No. 38 Bandung, Telepon: 0222038285, mobile 081321216511, e-mail: yuliantibisri@yahoo.com 


\section{Pendahuluan}

Hemodinamik sirkulasi pada wanita hamil berubah dalam posisi supine, terutama setelah memasuki trimester kedua. Pada posisi ini aorta akan tertekan karena itu curah jantung menurun secara nyata dan mengakibatkan penurunan perfusi uterus serta fetal. Dengan demikian, ibu dalam persalinan harus ditempatkan posisi miring ke kiri (left-lateral tilt). ${ }^{1}$ Lebih penting yaitu pengosongan uterus dengan melahirkan fetus penting untuk dapat menjamin resusitasi kardiopulmonal yang efektif pada ibu yang mengalami henti jantung. Dalam situasi ini, tujuan pengosongan uterus dengan melahirkan janin, bukan untuk menyelamatkan janin, tetapi menghilangkan kompresi aortokaval supaya resusitasi lebih efektif. ${ }^{1}$

Pada uterus dalam keadaan hamil terjadi obstruksi vena kava inferior dan juga vena femoralis pada $90 \%$ wanita, dan efek ini dapat dihilangkan dengan mengubah posisi ke posisi lateral recumbent. Sebagai tambahan, sirkulasi paravertebral dan kolateral akan memfasilitasi aliran balik vena dari kaki dan organ-organ pelvis yang dihambat oleh penekanan vena kava inferior. Berbagai penelitian juga menunjukkan bahwa uterus yang besar mampu menekan sistem arterial. Angiografi telah menunjukkan pengurangan aliran darah pada aorta serta pembuluh darah iliaka dan pembuluh darah yang lebih kecil (arteri renalis kanan, arteri ovarika, dan arteri lumbal). ${ }^{2}$

Supine hypotension syndrome (SHS) dijelaskan oleh Hansen pada tahun 1942. Kejadian SHS dapat terjadi mulai usia kehamilan trimester 2, namun $8 \%$ terjadi pada wanita usia kehamilan trimester ke-3 atau pada usia kehamilan 36-38 minggu. Keadaan SHS didefinisikan sebagai penurunan tekanan darah sistol sebesar 30\% atau lebih pada posisi terlentang dibandingkan dengan posisi lateral. Definisi lain SHS adalah penurunan tekanan darah rata-rata sebesar 15 $\mathrm{mmHg}$ dan peningkatan laju nadi $20 \mathrm{x} /$ menit dalam waktu 2 menit. ${ }^{3-7}$

Pada tahun 1964 dikemukakan SHS pada wanita hamil. Tekanan pada vena kava inferior oleh uterus yang hamil akan menyebabkan aliran balik vena (venous return) ke jantung tidak adekuat. Kolateral dari sistem vena kava tidak mencukupi aliran balik vena yang normal sehingga terjadi penurunan curah jantung sebagai kompensasinya yang akan meningkatkan vasokontriksi arteri. $4,5,7$

Keadaan SHS akan menimbulkan dampak pada ibu dan juga pada janinnya. Dampak yang ditimbulkan pada janin adalah distres janin, keadaan janin hipoksia, dan pada keadaan yang luar biasa dapat menyebabkan kematian janin, sedangkan pada ibu akan menimbulkan hipoperfusi otak. ${ }^{3}$

Supine hypotension syndrome disebabkan oleh karena penekanan pada aorta dan vena kava inferior oleh uterus yang gravid, dapat bermanifestasi yaitu sebagai takikardia, pucat, berkeringat, mual, serta hipotensi dan pusing. Pada posisi supine terjadi obstruksi vena kava inferior yang hampir lengkap pada kehamilan aterm. Darah kembali dari ektremitas bawah terjadi melalui vena vertebra intraoseus, vena paravertebralis, dan vena epidural. Akan tetapi, kembalinya darah melalui kolateral lebih sedikit daripada yang terjadi melalui vena kava inferior, menyebabkan penurunan tekanan atrium kanan. Pada posisi supine juga aorta tertekan oleh uterus yang dalam keadaan hamil dan pada aterm, posisi left lateral decubitus (posisi miring ke kiri) menyebabkan peningkatan aktivitas sistem saraf simpatis dan aktivitas vagal daripada posisisupine atau right lateral decubitus berkurang. Wanita hamil aterm dengan posisi supine mengalami $10-20 \%$ penurunan stroke volume dan curah jantung. Wanita aterm mengalami bradikardia dan penurunan tekanan darah bila dibaringkan dalam posisi supine sampai $15 \%$. Untuk terjadi hipotensi dan bradikardia membutuhkan waktu beberapa menit, serta bradikardia umumnya didahului oleh satu periode takikardia. ${ }^{2,7,8,9}$

Posisi lateral penuh mengurangi penekanan aortokaval, tetapi posisi ini tidak memungkinkan dilakukan seksio sesarea. Pada kebanyakan kasus posisi dilakukan miring ke kiri $15^{\circ}$ supaya dapat dilakukannya pembedahan. Pada posisi miring $15^{\circ}$, aorta dan vena kava masih tertekan, jadi sebagian kecil wanita masih mengalami SHS. Dokter spesialis anestesi harus selalu mengingat bahwa paling tidak harus dilakukan miring ke kiri minimal $15^{0} .{ }^{9}$

Pasien SHS mengalami penurunan velositas arteri karotid internal secara signifikan. Keadaan ini dapat disertai dengan pusing, mual, muntah sampai dengan syncope apabila velositas ratarata arteri karotid interna menurun hingga $10 \mathrm{~cm} /$ detik atau lebih. Pada wanita dapat terjadi $37 \%$ penurunan velositas arteri karotid interna. Keadaan SHS dapat diantisipasi dengan memposisikan wanita hamil pada posisi left lateral recumbent, left lateral decubitus, atau bahu yang dinaikkan. ${ }^{6}$

Pada banyak literatur telah dibahas SHS serta bagaimana mengatasinya, tetapi belum diketahui insidensi pada populasi wanita Indonesia. Tujuan 
penelitian ini adalah mengetahui insidensi SHS pada wanita hamil aterm di Bandung.

\section{Metode}

Penelitian observasional terhadap 200 pasien wanita hamil aterm yang akan dilakukan seksio sesarea elektif. Penelitian dilakukan di Rumah Sakit Ibu dan Anak Melinda Hospital Bandung, dari bulan Maret hingga Juli 2012. Pasien yang diikutsertakan dalam penelitian ini adalah pasien dengan kehamilan cukup bulan, status kehamilan pertama dan kedua, rentang usia 1640 tahun, tidak memiliki penyakit sertaan. Pasien dengan keadaan morbid obes atau obesitas tidak disertakan pada penelitian ini. Semua pasien diberi penjelasan mengenai penelitian dan menandatangani persetujuannya (informed consent).

Di ruang persiapan dilakukan pemasangan infus dan diberikan cairan kristaloid Ringer laktat sebanyak 500 cc sebagai pengganti puasa. Pada posisi miring kiri $45^{\circ}$ dengan menggunakan bantal dilakukan pengukuran tekanan darah sistol, diastol, tekanan darah rata-rata, laju nadi, dan saturasi oksigen setiap menit selama 5 menit. Setelah 5 menit dalam posisi miring kiri $45^{\circ}$ kemudian pasien berbaring tertentang dan dilakukan pengukuran seperti tadi. Tekanan darah, laju nadi, dan $\mathrm{SpO}_{2}$ diukur menggunakan tensimeter automatis non invasive DINAMAP PRO 1000.

Perhitungan data dasar usia, berat badan, tinggi badan, dan gravida ke berapa dihitung nilai rata-rata dan standar deviasinya, sedangkan data tekanan darah sistol, diastol, tekanan darah rata-rata, laju nadi, dan saturasi oksigen dihitung dengan menggunakan uji-t dan Pearson serta dinyatakan bermakna apabila nilai $\mathrm{p}<0,05$.
Tabel 1 Karakteristik Umum Subjek

\begin{tabular}{lc}
\hline \multicolumn{1}{c}{ Variabel } & Rata-rata \pm SB \\
\hline Usia (tahun) & $30,33(4,63)$ \\
Berat badan $(\mathrm{kg})$ & $69,31(9,68)$ \\
Tinggi badan $(\mathrm{cm})$ & $158,00(6,13)$ \\
Gravida & G1 dan G2 \\
\hline
\end{tabular}

Keterangan: $n=200$, SB: simpangan baku

\section{Hasil}

Hasil penelitian yang dilakukan di Rumah Sakit Ibu dan Anak Melinda Hospital Bandung pada 200 wanita hamil aterm yang sesuai dengan kriteria penelitian. Hasil penelitian terlihat pada tabel dan gambar di bawah ini. Dari karakteristik umum (usia, berat badan, tinggi badan, status kehamilan) didapatkan nilai seperti terlihat pada Tabel 1. Setelah dilakukan perhitungan statistik tidak didapatkan nilai yang signifikan sehingga sampel dapat dilakukan penelitian dan kemudian dilakukan perhitungan statistik selanjutnya. Pasien dengan rentang usia 16-40 tahun dan tidak memiliki penyakit penyerta memiliki respons fisiologi yang dianggap sama.

Tabel 2 memperlihatkan data tekanan darah sistol, diastol, rata-rata, laju nadi, dan $\mathrm{SpO}_{2}$ kedua kelompok (posisi supine dan posisi miring ke kiri $45^{\circ}$ ). Dari hasil perhitungan statistik didapatkan nilai $\mathrm{p}>0,05$ memperlihatkan bahwa hasilnya tidak berbeda bermakna. Hasil perhitungan ini memperlihatkan bahwa tidak ada perbedaan tekanan darah sistol, diastol, rata-rata, laju nadi, serta $\mathrm{SpO}_{2}$ pada posisi supine dan posisi miring ke kiri $45^{\circ}$.

Gambar 1 menunjukkan hasil perhitungan perbandingan tekanan darah sistol, diastol, dan tekanan darah rata-rata (MAP) antara posisi

Tabel 2 Tekanan Darah Sistol, Diastol, Rata-Rata, Laju Nadi, $\mathrm{SpO}_{2}$ pada Posisi Supine dan Miring Kiri 300 ${ }^{\circ}$

\begin{tabular}{lccc}
\hline \multicolumn{1}{c}{ Parameter } & $\begin{array}{c}\text { Supine } \\
\text { Rata-rata } \pm \text { SB }\end{array}$ & $\begin{array}{c}\text { Miring Kiri 30 } \\
\text { Rata-rata } \pm \text { SB }\end{array}$ & p \\
\hline Tekanan darah sistol (mmHg) & $113,49(13,20)$ & $105,20(12,08)$ & 0,93 \\
Tekanan darah diastol (mmHg) & $69,05(7,31)$ & $58,58(7,73)$ & 0,51 \\
Tekanan darah rata-rata & $84,59(8,38)$ & $75,87(8,82)$ & 0,62 \\
(mmHg) & & & 0,86 \\
Laju nadi (xmenit) & $88,95(12,19)$ & $86,26(11,47)$ & 0,07 \\
$\mathrm{SpO}_{2}(\%)$ & $99,95(1,11)$ & $99,64(0,67)$ & \\
\hline
\end{tabular}

Keterangan: N=200; Signifikan bila p<0,05; SB: Simpangan Baku 

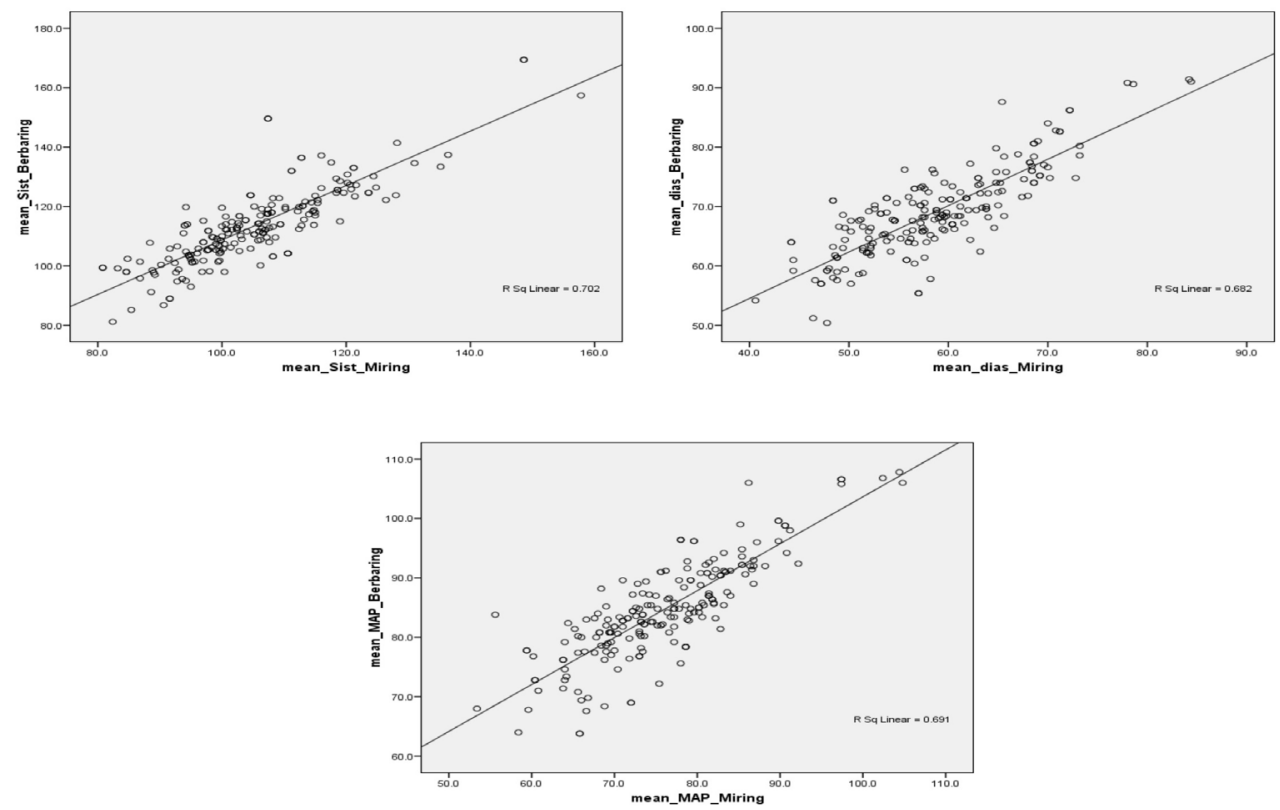

\section{Gambar 1 Tekanan Darah Sistol, Diastol, dan Tekanan Darah Rata-rata (Mean Arterial Pressure/ MAP)}

supine dan posisi lateral $45^{\circ}$. Perhitungan tekanan darah sistol, diastol, dan tekanan darah rata-rata (MAP) menggunakan Pearson dengan nilai $\mathrm{p}>0,05$ memperlihatkan tidak bermakna, artinya tidak ada perbedaan tekanan darah (sistol, diastol, dan rata-rata) pada wanita hamil aterm baik dalam kedaan posisi supine ataupun posisi miring $45^{\circ}$.

Gambar 2 merupakan hasil perhitungan laju nadi dan saturasi oksigen $\left(\mathrm{SpO}_{2}\right)$ dengan mempergunakan perhitungan Pearson. Hasil perhitungan laju nadi dan $\mathrm{SpO}_{2}$ menunjukkan nilai $p>0,05$, artinya tidak berbeda bermakna. Laju nadi dan $\mathrm{SpO}_{2}$ pada wanita hamil aterm tidak memiliki perubahan yang nyata baik dalam keadaan posisi supine ataupun posisi miring $45^{0 .}$

\section{Pembahasan}

Pada tahun 1964 telah ditunjukkan berdasar atas pemeriksaan radiologis bahwa vena kava tertutup sebagian pada kehamilan aterm bila ibu dalam posisi supine. Pada tahun 1966, penelitian
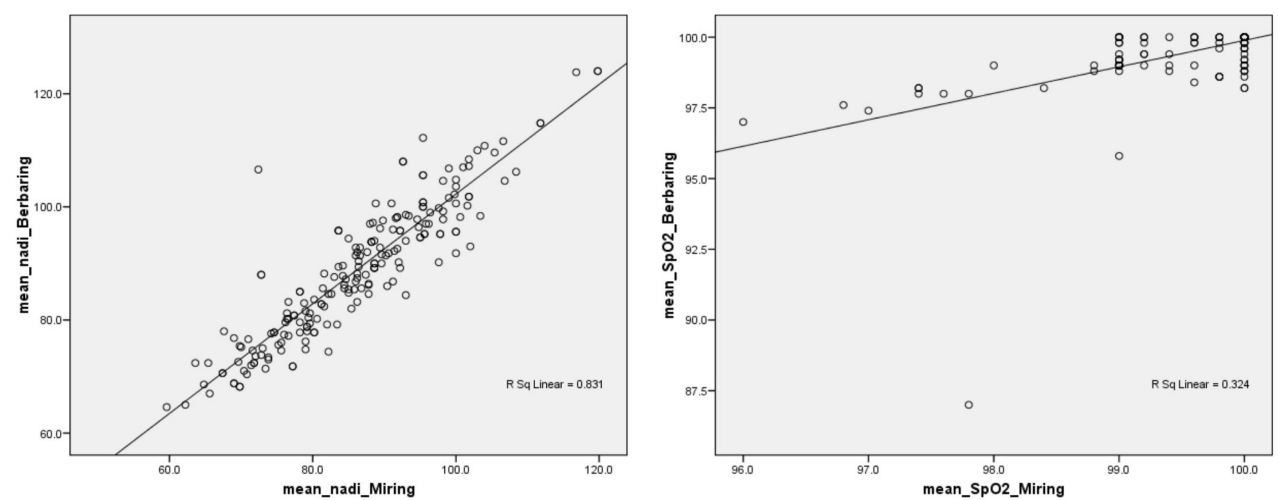

Gambar 2 Laju Nadi dan Saturasi Oksigen ( $\left.\mathrm{SpO}_{2}\right)$ 
dengan menggunakan parameter tekanan arteri femoralis dan brakial menunjukkan bahwa aorta juga tertekan pada wanita hamil aterm dengan posisi supine. Pada penelitian tahun 1968 penekanan aorta oleh uterus yang gravid dibuktikan dengan angiografi. ${ }^{5}$

Satu laporan kasus pasien wanita hamil 37 minggu ditemukan meninggal di rumahnya dalam posisi terlentang dan autopsi menunjukkan kemungkinan kematian akibat SHS karena tidak ditemukan hal-hal lain yang dapat menyebabkan kematiannya. Supine hypotension syndrome dapat menimbulkan hipoperfusi otak dan hipoksia. ${ }^{10}$

Supine hypotension syndrome didefiniskan sebagai hipotensi yang dihubungkan dengan posisi supine dan memengaruhi $8 \%$ wanita hamil pada trimester kedua dan ketiga. Keluhan yang terjadi dapat berupa mual, pusing, cemas, dan kepala terasa melayang. Kriteria objektif berupa penurunan tekanan darah arteri rata-rata $>15$ mmHg, penurunan tekanan sistol $15-30 \mathrm{mmHg}$, dengan peningkatan laju nadi $20 \mathrm{kali} / \mathrm{menit}$ di atas nilai dasar. ${ }^{7}$

Penurunan aliran balik vena diakibatkan karena obstruksi aliran darah vena kava oleh uterus yang gravid yang akan terlihat pada wanita hamil trimester akhir pada posisi supine. Untungnya, sindrom ini tidak terjadi pada semua atau kebanyakan wanita hamil. Salah satu kemungkinan teorinya adalah beberapa wanita diproteksi dari penurunan aliran balik vena ini oleh perkembangan sirkulasi kolateral pelvis paravertebra. ${ }^{7}$ Kemungkinan proteksi lain adalah perubahan pada baroreflex gain yang terjadi pada kehamilan. Pada kehamilan normal barareflex gain menurun yang menumpulkan respons kompensasi atau laju nadi terhadap perubahan tekanan darah yang dirasakan oleh arkus aorta dan baroreseptor karotid. Dalam kondisi normal, penurunan aliran balik vena akibat obstruksi oleh uterus yang gravid akan menurunkan stroke volume dan menstimulasi baroreseptor. Respons kompensatori yang normal adalah meningkatkan laju nadi untuk dapat mempertahankan curah jantung. Kalau baroreflex gain ditekan secara abnormal, kemudian laju nadi tidak cukup untuk mempertahankan curah jantung maka tidak ada efek proteksi dan terjadilah SHS. Penelitian ini menunjukkan bahwa penurunan baroreflex gain sebagai kemungkinan penyebab SHS tidak dapat dibuktikan dan sirkulasi kolateral tidak adekuat yang menyebabkan SHS. ${ }^{7}$

Selama lebih dari 50 tahunSHS di negara Eropa merupakan hal yang patut dipertimbangkan pada wanita hamil yang diposisikan berbaring. Pada wanita hamil cukup bulan (36-38 minggu) diposisikan berbaring dapat terjadi SHS. Hasil penelitian ini menunjukkan tidak terjadi SHS pada wanita cukup bulan pada posisi terlentang di negara Indonesia.

Onset terjadinya hipotensi setelah posisi supine umumnya 3-10 menit, tetapi ada rentang waktu yang lebar. Suatu penelitian menemukan penurunan tekanan sistol dari $100 \mathrm{mmHg}$ ke 85 $\mathrm{mmHg}$ dalam setengah menit dan ke $50 \mathrm{mmHg}$ dalam 2 menit, sedangkan pada pasien yang lain setelah 30 menit dalam posisi supine. ${ }^{11,12}$

Simtom/keluhan yang ditemukan pada SHS antara lain serasa mau pingsan, pusing, dispnea, gelisah, mual, muntah, rasa tidak enak atau nyeri di dada atau abdomen, gangguan penglihatan, parestesi di anggota badan, sakit kepala, rasa dingin di kaki, lemas, telinga mendenging, serta merasa akan mati. ${ }^{11,12}$

Gejala klinis adalah pucat atau sianosis, twitching otot, hiperpnea, kulit dingin, pada kasus berat nadi tidak teraba dan tidak sadar. ${ }^{11}$ Penelitian lain menemukan tidak ada keluhan pada pasien dengan tekanan darah 80/60 mmHg. ${ }^{6,11}$ Gejala SHS berupa penurunan tekanan darah dan peningkatan atau penurunan laju nadi. Berbagai cara dapat dilakukan dengan tujuan mengurangi atau mencegah SHS, salah satunya yaitu memposisikan miring ke kiri. ${ }^{12}$

Penyebab lain kejadian SHS dihubungkan dengan keadaan hipovolemia serta hipotensi sebelumnya. Terapi yang dapat dilakukan pada keadaan SHS selain perubahan posisi adalah pemberian $\mathrm{NaCl} 0,9 \%$ atau RL (cairan kristaloid) sampai dengan pemberian vasokonstriktor. ${ }^{12}$

Penurunan aliran balik vena dan curah jantung akibat penekanan pada aortokaval pada posisi berbaring pada kehamilan cukup bulan akan mengaktifkan simpatis dan juga penekanan aktivitas vagal. Sebaliknya, pada wanita yang tidak hamil memiliki aktivitas vagal tinggi dan aktivitas simpatis rendah, sedangkan laju nadi terjadi penurunan pada posisi miring (lateral $45^{\circ}$ ) bukan pada posisi berbaring. ${ }^{6}$

Saturasi oksigen wanita hamil pada posisi berbaring dan mengalami SHS tidak mengalami perubahan apabila kurang dari 5 menit. Pada penelitian ini saturasi oksigen $\left(\mathrm{SpO}_{2}\right)$ tidak mengalami perbedaan antara posisi berbaring dan miring. ${ }^{6}$ Pada penelitian ini tidak terdapat perbedaan tekanan darah sistol, diastol, ratarata, $\mathrm{SpO}_{2}$, dan laju nadi antara posisi supine dan miring ke kiri $45^{\circ}$. Keadaan ini mungkin karena sistem kolateral yang adekuat sehingga tidak terjadi penurunan aliran balik vena ke jantung maka tidak terjadi SHS pada posisi supine. Jumlah sampel pada penelitian ini hanya 200 pasien 
gravida aterm sehingga keterbatasan penelitian adalah belum dapat menjawab berapa kejadian SHS pada wanita Indonesia bila jumlah sampel mencapai 10 ribu orang.

Simpulan, tidak terdapat perbedaan tekanan darah, laju nadi, dan $\mathrm{SpO}_{2}$ wanita hamil aterm antara posisi supine dan miring ke kiri $45^{\circ}$ sehingga tidak diperlukan perubahan posisi pasien saat akan dilakukan seksio sesarea.

\section{Daftar Pustaka}

1. Tan EK, Tan EL. Alterations in physiology and anatomy during pregnancy. Best Pract Res Clin Obstet Gynaecol. 2013;27(6):791-802.

2. Ouzounian JG, Elkayam U. Physiologic changes during normal pregnancy and delivery. Cardiol Clin. 2012;30(3):317-29.

3. Solanki GA. Review on supine hypotension syndrome. IJPR. 2012;2(2):81-2.

4. Christiansen LR, Collins KA. Pregnancyassociated deaths: a 15 year retrospective study and overall review of maternal pathophysiology. Am J Forensic. 2006;27(1): 11-9.

5. Warwick D, Kee N. Prevention of maternal hipotension after regional anaesthesia for caesarean section. Curr Opin Anaesthesiol. 2010;23(3):304-9.

6. Armstrong S, Fernando R, Columb M, Jones T. Cardiac index in term pregnant women in the sitting, lateral, and supine positions: an observational, crossover study. Anesth
Analg. 2011;113(3):318-22.

7. McDonald S, Fernando R, Ashpole K, Columd M. Maternal cardiac output changes after crystalloid or colloid coload following spinal anaesthesia for elective cesarean delivery: a randomized controlled trial. Anaesth Analg. 2011;113(4):803-10.

8. López-Maya L, Francisco Lina-Manjarrez F. Prevention of supine hypotension in pregnant women undergoing cesarean section with peridural blockage;preload versus rapid load. Revista Mexicana Anestesiología. 2008;31(1):21-5.

9. Field JM, Catallo K, Au AK, Rotte M, Leventhal D, Weiner S, dkk. Resuscitation of pregnant patient: what is the effect of patient positioning on inferior vena kava diameter? Resuscitation. 2013;84(3):304-8.

10. De-Giorgio F, Grassi VM, Vetrugno G, d'Aloja E, Pascali VL, Arena V. Supine hypotensive syndrome as the probable cause of both maternal and fetal death. J Forensic Sci. 2012;57(6):1646-9.

11. Stewart A, Fernando R, McDonald S, Hignett $\mathrm{R}$, Jones T, Columb M. The dose-dependent effect of phenylephrine for elective caesarean delivery under spinal anesthesia. Anesth Analg. 2010;111(5):1230-7.

12. Segal N, Page DI, Lick CJ, Doering DD, Yannopoulos D. Use of impedance threshold device to treat severe hypotension in a pregnant woman: case report and review of the literature. J Emerg Med. 2013;45(4): e113-5. 